\title{
Neonatal resuscitation: evolving strategies
}

\author{
Payam Vali ${ }^{1,2^{*}}$, Bobby Mathew ${ }^{1,2}$ and Satyan Lakshminrusimha $a^{1,2}$
}

\begin{abstract}
Birth asphyxia accounts for about 23\% of the approximately 4 million neonatal deaths each year worldwide (Black et al., Lancet, 2010, 375(9730):1969-87). The majority of newborn infants require little assistance to undergo physiologic transition at birth and adapt to extrauterine life. Approximately $10 \%$ of infants require some assistance to establish regular respirations at birth. Less than $1 \%$ need extensive resuscitative measures such as chest compressions and approximately 0.06\% require epinephrine (Wyllie et al. Resuscitation, 2010, 81 Suppl 1:e260-e287). Transition at birth is mediated by significant changes in circulatory and respiratory physiology. Ongoing research in the field of neonatal resuscitation has expanded our understanding of neonatal physiology enabling the implementation of improved recommendations and guidelines on how to best approach newborns in need for intervention at birth. Many of these recommendations are extrapolated from animal models and clinical trials in adults. There are many outstanding controversial issues in neonatal resuscitation that need to be addressed. This article provides a comprehensive and critical literature review on the most relevant and current research pertaining to evolving new strategies in neonatal resuscitation. The key elements to a successful neonatal resuscitation include ventilation of the lungs while minimizing injury, the judicious use of oxygen to improve pulmonary blood flow, circulatory support with chest compressions, and vasopressors and volume that would hasten return of spontaneous circulation. Several exciting new avenues in neonatal resuscitation such as delayed cord clamping, sustained inflation breaths, and alternate vasopressor agents are briefly discussed. Finally, efforts to improve resuscitative efforts in developing countries through education of basic steps of neonatal resuscitation are likely to decrease birth asphyxia and neonatal mortality.
\end{abstract}

Keywords: Cord clamping, Meconium, Ventilation, Sustained inflation, Chest compressions, Epinephrine, Oxygen

\section{Introduction}

Among more than 130 million births per year globally, approximately ten percent of newborns require some form of intervention immediately at birth. It is estimated that $25 \%$ of approximately 4 million neonatal deaths worldwide are secondary to birth asphyxia [1-4]. Unlike the emphasis on restitution of cardiac activity in adult resuscitation, the Working Group on Pediatric Resuscitation has recommended that resuscitation of newborns should focus on ventilation of the lungs [5]. By 1985, the American Academy of Pediatrics (AAP) and American Heart Association (AHA) expressed a joint commitment to develop a training program aimed at neonatal resuscitation. The first edition of the Neonatal Resuscitation Textbook was published in 1987. Since that time, the

\footnotetext{
* Correspondence: payam.vali@gmail.com

${ }^{1}$ Department of Pediatrics (Neonatology), University at Buffalo, Buffalo, NY, USA

Women and Children's Hospital of Buffalo, 219 Bryant St, Buffalo, NY 14222 USA
}

International Liaison Committee on Resuscitation (ILCOR) has continued to develop and publish a consensus on the science of resuscitation approximately every five years [6]. The initial recommendations were based predominantly on opinions from experts in the field. Through extensive research and review of literature in the past two decades, neonatal resuscitation guidelines are increasingly derived from experimental and experiential evidence from simulation manikins, animal models, randomized clinical trials [7-9], and systematic clinical observation [10]. However, certain aspects of the current guidelines remain controversial given the difficulties in conducting randomized clinical trials due to the infrequent and often unpredictable need for extensive resuscitation. Many research studies in neonatal resuscitation are conducted using postnatal, term animal models that fail to adequately depict the transitioning fetal circulation, an open ductus arteriosus, fluid-filled lungs and, in case of preterm birth, premature lungs. Deleterious effects associated with various steps of neonatal resuscitation such as

\section{Biomed Central}

(c) 2015 Vali et al.; licensee BioMed Central. This is an Open Access article distributed under the terms of the Creative Commons Attribution License (http://creativecommons.org/licenses/by/4.0), which permits unrestricted use, distribution, and reproduction in any medium, provided the original work is properly credited. The Creative Commons Public Domain Dedication waiver (http://creativecommons.org/publicdomain/zero/1.0/) applies to the data made available in this article, unless otherwise stated. 
hyperoxemia [10], barotrauma due to positive pressure ventilation (PPV), mechanical effects of chest compressions (CCs) and resuscitative medications [11] are being increasingly recognized. Hence, the guidelines for neonatal resuscitation focus on ventilation while establishing a functional residual capacity (FRC) without causing lung injury, optimizing oxygen delivery to the tissues without inducing toxicity, and hastening return of spontaneous circulation with effective CCs and drug delivery. The physiological basis of current and planned resuscitative measures is outlined below. A summary of important changes in the current version of neonatal resuscitation guidelines is shown in Figure 1.

\section{Review}

\section{Fetal circulation, transition at birth, delayed}

\section{(Physiological) Cord Clamping and Temperature Control}

Relatively oxygen-rich blood $\left(\mathrm{PaO}_{2} 20-40 \mathrm{~mm} \mathrm{Hg}\right)$ from the umbilical vein entering the inferior vena cava (IVC) tends to stream and does not completely mix with the less oxygenated blood that enters the IVC from the lower half of the body (Figure 2A). This oxygen-rich blood is then preferentially diverted to the left ventricle through the foramen ovale to the left atrium. The fetal pulmonary venous return is low due to high pulmonary vascular resistance.
Hence, the umbilical venous return is the chief component of left ventricular preload and determines oxygen delivery to the brain and heart (Figure 2A) [12]. In the human fetus, umbilical blood flow increases proportional to fetal weight gain and remains constant around $110-125 \mathrm{~mL} / \mathrm{min} / \mathrm{kg}$. The fetal biventricular cardiac output is approximately $450 \mathrm{~mL} / \mathrm{min} / \mathrm{kg}$ and, thus, umbilical blood flow represents about $30 \%$ of the cardiac output [13].

The practice of early umbilical cord clamping started in the 20th century with an increasing number of hospital births and deliveries being conducted by obstetricians. In spite of little evidence or physiologic rationale to support immediate cord clamping, it remains the standard practice in the United States [14,15]. Numerous studies on delayed cord clamping have indicated benefits in improved hemodynamics, higher hematocrit levels, reduced need for blood transfusions and reduced incidence of intraventricular hemorrhage [16-20]. Delayed cord clamping and placental transfusion are associated with increased bilirubin levels without an increased need for phototherapy in preterm infants [20]. In term infants, there is evidence to suggest that delayed cord clamping is associated with increased need for phototherapy [21]. However, there is inconsistency with this association, as

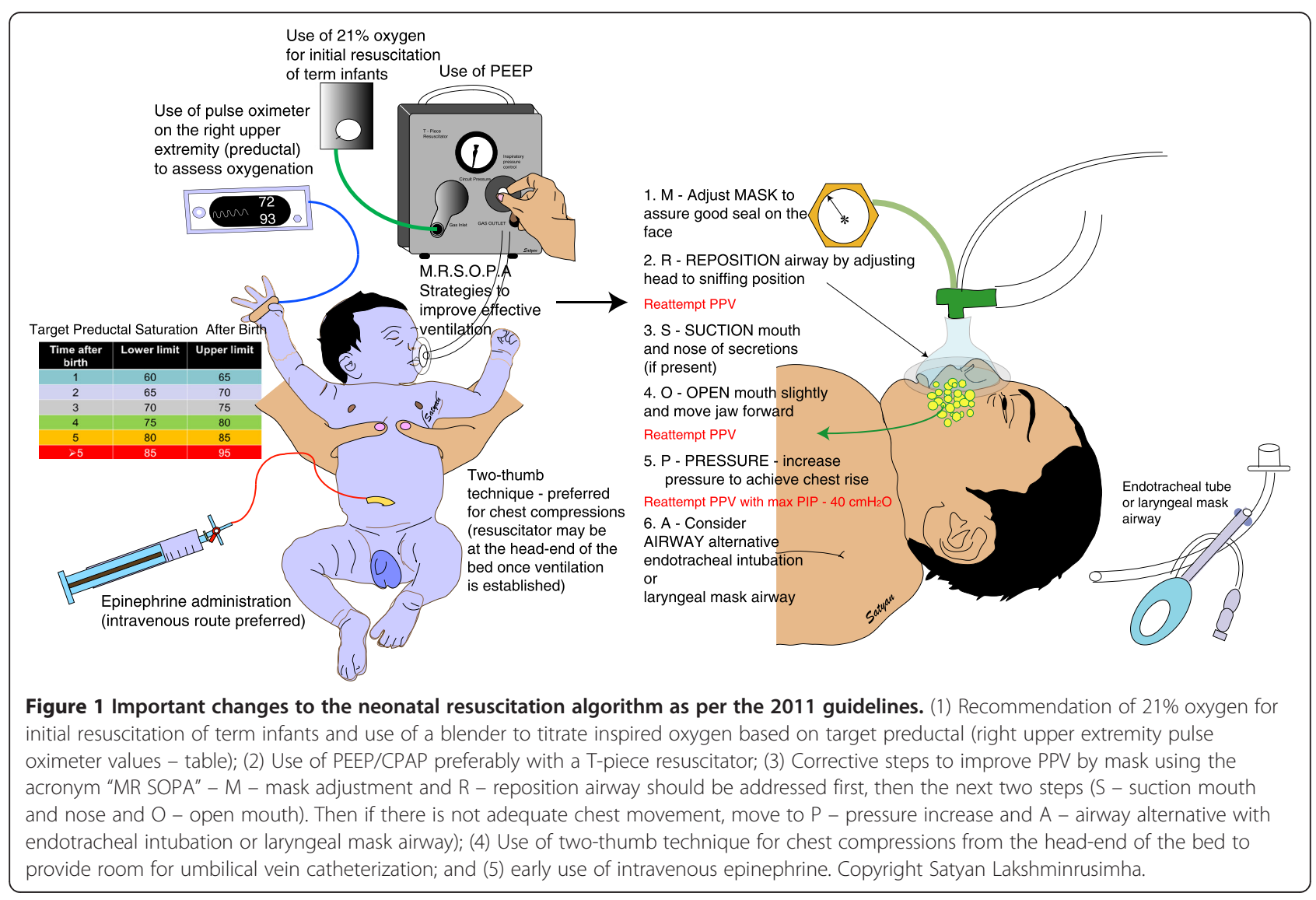




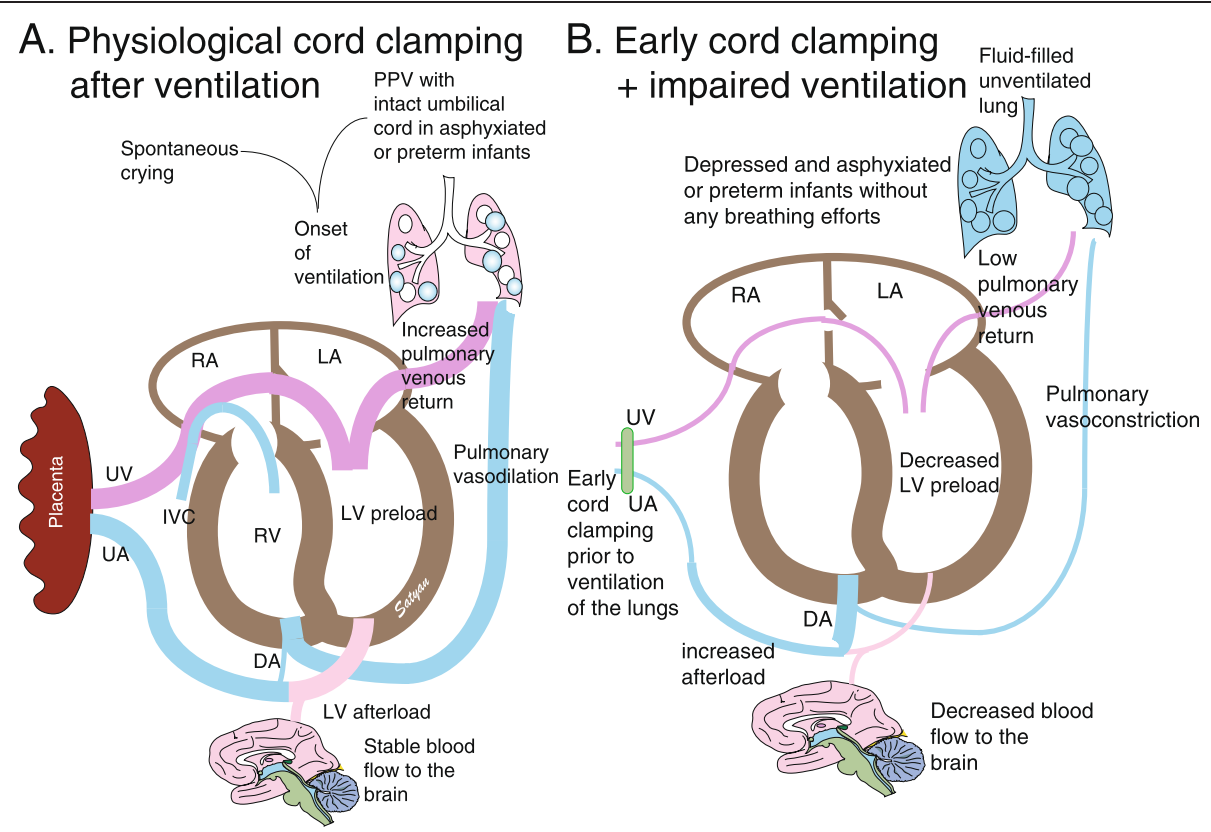

Figure 2 Effects of cord clamping on hemodynamics. An intact umbilical cord allows continuous umbilical venous flow to the ventricles. With the concomitant initiation of breathing through crying or PPV, PVR decreases allowing increased blood flow to the lungs (decreased right to left shunt through the DA) as well as increased venous return to the LV. The unclamped UA prevents a sudden increase in afterload. This results in improved cardiac output (A). Conversely, immediate cord clamping restricts flow to the ventricles. With failure to establish ventilation, PVR remains high and compromises pulmonary blood flow (increased right to left DA shunt) and venous return to the left ventricle. Thus, decreased filling of the left ventricle (preload) and increased afterload (due to removal of low-resistance placenta) compromise cardiac output (B). DA ductus arteriosus, PPV positive pressure ventilation, LA left atrium, RA right atrium, LV left ventricle, UA umbilical artery, UV umbilical vein. Copyright Satyan Lakshminrusimha.

many large trials do not show a link between the need for phototherapy and delayed cord clamping [18,22]. Based on the current evidence, the benefits of delayed cord clamping appear to outweigh the risks associated with placental transfusion.

Term, non-asphyxiated, infants cry and initiate ventilation soon after birth prior to clamping the umbilical cord (Figure 2A). A recent study investigating the physiologic effects of ventilation on cord clamping in preterm lambs shows a significant improvement in cardiovascular stability if ventilation is commenced prior to cord clamping [23]. Umbilical cord clamping prior to ventilation of the lungs causes cessation of umbilical venous flow to the heart resulting in an abrupt drop in left ventricular filling volume, while occlusion of the umbilical artery increases left ventricular afterload (Figure 2B). In the absence of ventilation, pulmonary vascular resistance remains high resulting in decreased pulmonary blood flow and return of blood back to the left ventricle. Therefore, in the absence of established ventilation, cord clamping puts a significant strain on the newborn's cardiovascular system to overcome increased afterload in the setting of decreased ventricle filling volume [14,23]. "Delaying" cord clamping until ventilation is established is "physiologic" cord clamping.
Due to growing evidence to support the beneficial effects of delayed cord clamping, ILCOR currently recommends that the cord should not be cut for at least one minute in infants not requiring resuscitation and the ACOG advocates delayed umbilical cord clamping in preterm neonates when feasible $[24,25]$. It is important to emphasize the importance of improved prognosis in newborns allowed to undergo a smooth transition at birth by delaying cord clamping until ventilation (spontaneous or PPV) of the lungs is established (Figure 2).

Newborns, particularly those born prematurely, are at increased risk of hypothermia (temperature $<36^{\circ} \mathrm{C}$ ) owing to their high surface area to volume ratio and the increased evaporative fluid losses from the skin, which is associated with increased morbidity and mortality [26,27]. Drying the baby with prewarmed towels and radiant warmers are not sufficient to prevent heat loss in premature infants and the current guidelines recommend placing newborn infants $<28$ weeks in a polyethylene wrap or bag immediately after birth keeping the temperature of the delivery room at $26^{\circ} \mathrm{C}[24,28]$. Early skin-to-skin contact is a another technique to prevent heat loss in premature newborns [29], a viable option in resource-limited settings. Though the evidence does not suggest an increased risk of hypothermia in preterm infants who have 
undergone delayed cord clamping (30-60 seconds) [20], there is a potential risk of a drop in core temperature if measures are not taken to prevent heat loss in extreme premature infants during delayed cord clamping especially if the delay exceeds 60-120 seconds. The healthcare providers need to be cognizant of this potential adverse event. Rapid milking of the umbilical cord at birth may provide the benefits of placental transfusion while limiting the risk of hypothermia and requires further study [30].

\section{Meconium stained amniotic fluid}

The significance and perinatal management of meconium stained amniotic fluid (MSAF) has evolved over time. Routine amnioinfusion, oral/nasal and tracheal suctioning [31-34] were considered to reduce the incidence of meconium aspiration syndrome (MAS) by diluting meconium consistency, decreasing cord compression and removing meconium [35]. Large, multicenter, randomized trials concluded that amnioinfusion, oral, nasal and/or tracheal suctioning in vigorous infants did not alter the incidence of MAS (Figure 3) [7-9].

The Neonatal Resuscitation Program (NRP) protocol for delivery room management no longer recommends tracheal suctioning for vigorous infants [5]. Approximately $20-30 \%$ of infants born through MSAF are depressed at birth with an Apgar score of 6 or less at 1 minute of age [36]. Babies exposed to MSAF who have respiratory depression at birth have a higher incidence of MAS [37]. If a baby is born through MSAF, has depressed respirations, decreased muscle tone, and/or a heart rate below 100/min, intubation and direct suctioning of the trachea soon after delivery is indicated before breaths have occurred.

Recent studies in animal models and pilot clinical trials have questioned the benefit of tracheal suctioning in non-vigorous infants born through MSAF. In a lamb model of asphyxia, depression and acute meconium aspiration, tracheal suctioning improved ventilation and oxygenation but did not decrease pulmonary vascular resistance and elevated left atrial pressure possibly as a result of left ventricular dysfunction. The process of tracheal suctioning significantly delayed onset of resuscitation with PPV (47 \pm 3 seconds in the no-suction and $146 \pm 11$ seconds in the suction group, $\mathrm{p}<0.001$ ) [Lakshminrusimha et al. Pediatric Research 2014 in press]. A pilot clinical trial evaluating tracheal suctioning in term infants born through MSAF who were not vigorous at birth was presented in an abstract form at the Pediatric Academic Societies meeting in 2014 (E-PAS2014:4680.1). This study randomized 175 neonates to tracheal suctioning $(\mathrm{n}=87)$ and no tracheal suctioning $(n=88)$. There was no difference in the incidence of death and/or MAS (32\% in the tracheal suctioning and $26 \%$ in the no tracheal suctioning groups, respectively). These results may influence future guidelines on the approach to non-vigorous infants born to mothers with MSAF.

\section{Ventilation \\ Fetal lung fluid and first breaths}

Active chloride secretion underpins fetal lung liquid secretion and it is critical for lung growth in utero. In late gestation, a rise in fetal glucocorticoids and thyroid hormones readies the sodium absorptive mechanism [38]. Stress of uterine contractions and birth raises fetal epinephrine, which triggers the mechanism responsible for liquid secretion to liquid absorption through the activation of sodium channels in the lung epithelium. After birth, a rise in ambient oxygen augments sodium absorption, which completes the transition to the postnatal state [38]. The process of emptying the lung fluid that

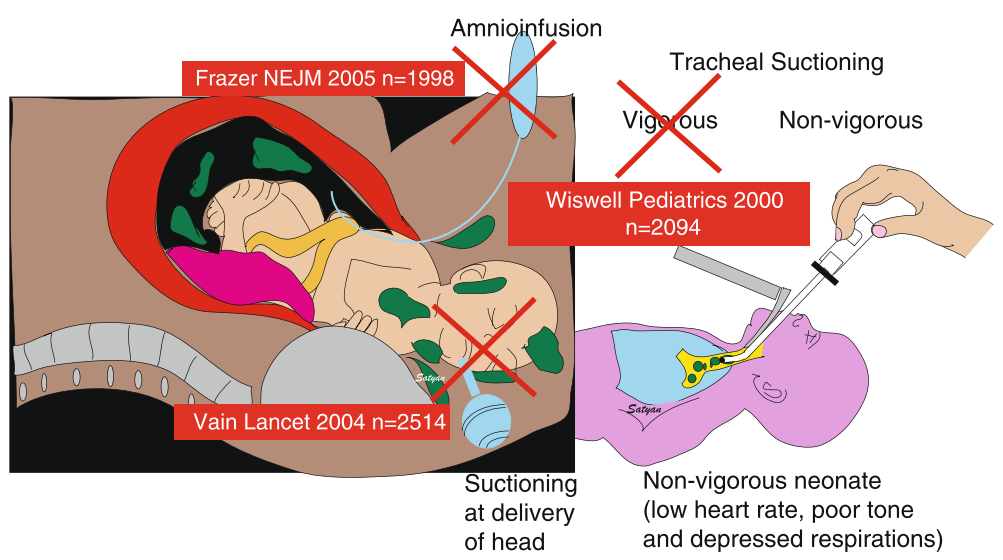

Figure 3 Management of meconium-stained amniotic fluid (MSAF). Randomized controlled trials (RCT) with large numbers of mothers and neonates ( $\mathrm{n}$ - shown in parentheses for each study in a red box) do not support amnioinfusion or oropharyngeal suction following delivery of the head or tracheal suction in the vigorous newborns delivered through meconium-stained amniotic fluid (MSAF). The current guidelines recommend tracheal suctioning only for neonates that are not vigorous and born through MSAF. Copyright Satyan Lakshminrusimha. 
begins before birth is augmented by labor and is mostly complete after two hours of independent breathing [39]. During parturition, breathing movements are inhibited, but severe asphyxia can induce gasping movements resulting in the aspiration of meconium during delivery. At birth, breathing results from removal of placental humoral inhibitory factors, cooling, rising carbon dioxide concentrations, and catecholamine surge and induction of genes encoding for substances important for breathing (substance P) [40].

During the first breaths, term infants can generate very high inspiratory (range -28 to $-105 \mathrm{~cm} \mathrm{H}_{2} \mathrm{O}$; mean $-52 \mathrm{~cm}$ $\mathrm{H}_{2} \mathrm{O}$ ) and expiratory (range 18-115 $\mathrm{cm} \mathrm{H}_{2} \mathrm{O}$; mean $71 \mathrm{~cm}$ $\mathrm{H}_{2} \mathrm{O}$ ) pressures to achieve an average inspired volume of $40 \mathrm{~mL}$ [41]. First breaths tend to be deeper and longer than subsequent breaths, and are characterized by a short deep inspiration followed by a prolonged expiratory phase through a partially closed larynx, known as expiratory braking [42]. This phenomenon is also observed in infants treated with continuous positive airway pressure (CPAP), frequently slowing and extending the time for expiration [43]. Crying in term and preterm infants immediately after birth also uses expiratory braking and facilitates lung volume recruitment [44]. This observation of spontaneously prolonged initial breaths at birth has prompted investigators to study the effects of a sustained inflation (SI) in apneic infants.

\section{Sustained Inflation (SI)}

The optimal ventilation strategy immediately after birth for depressed infants with no spontaneous respiratory effort and liquid-filled lungs is not known. Increasing evidence suggests that SI provided at the onset of resuscitation achieves better lung aeration. Though the duration and pressure of the SI remains to be determined, the new European Resuscitation Council Guidelines recommend SI for the initial ventilation of apneic term and preterm infants [28]. A study in preterm rabbits using SI of 20 seconds, followed by PPV with positive end-expiratory pressure (PEEP), resulted in a rapid increase in FRC and uniformly aerated lungs [45]. In preterm lambs, SI facilitates establishment of pulmonary blood flow immediately after birth and improves cerebral blood flow stability [46]. A study in near term asphyxiated lambs has shown that a single $\mathrm{SI}$ of $35 \mathrm{~cm} \mathrm{H}_{2} \mathrm{O}$ for 30 seconds immediately after birth improves speed of circulatory recovery and lung compliance [47]. In a premature newborn lamb model, no difference in early markers of lung injury were observed with volume-targeted SI ( $15 \mathrm{~mL} / \mathrm{kg}$ volume) when compared to a pressure-limited SI $\left(40 \mathrm{~cm} \mathrm{H}_{2} \mathrm{O}\right)$ [48]. In the clinical setting, Lindner et al. randomized 61 preterm infants $<29$ weeks gestation to either receive a 15 -second SI (20-30 $\mathrm{cm} \mathrm{H}_{2} \mathrm{O}$ ) or nasal-intermittent mandatory ventilation in the delivery room and reported no difference in adverse effects or the need for mechanical ventilation [49]. Lista et al. have demonstrated reductions in the rates of mechanical ventilation, surfactant, postnatal steroid use, a reduction in the mean duration of ventilation, and bronchopulmonary dysplasia (BPD) in all survivors among the infants that were $\leq 32$ week gestation when an initial 15 -second SI followed by nasal CPAP was given in the delivery room [50]. The result of these clinical studies need to be interpreted with caution as SI was only one factor among other changes brought about in the delivery room during these trials. Clinical trials evaluating the efficacy of SI in preterm infants are warranted and are ongoing [51]. The potential benefits of SI are shown in Figure 4.

\section{Assisted ventilation and ventilation devices in the delivery room}

In many instances, newborns may require ventilatory support shortly following birth, which can be broadly categorized into two groups: (1) respiratory depression and/or inadequate respiratory effort: conditions that lead to hypopnea or apnea including, but not limited to, central nervous system abnormalities (including neuromuscular disorders), asphyxia and/or sepsis, and (2) respiratory distress: conditions that lead to increased work of breathing, including respiratory distress syndrome, retained fetal lung fluid, airleak syndromes, pleural effusions, and congenital anomalies. The purpose of assisted ventilation is to create and maintain a functional residual capacity (FRC), and to deliver an adequate tidal volume $\left(\mathrm{V}_{\mathrm{T}}\right)$ to facilitate gas exchange and stimulate breathing, while minimizing lung injury. This can be achieved by means of CPAP, PPV and SI using any of three resuscitative devices: (1) a T-piece resuscitator, (2) a self-inflating bag or (3) a flow-inflating bag. In spontaneously breathing infants, the increase in intrathoracic pressure during expiration through a narrow glottis can be simulated by applying PEEP by means of CPAP to help them maintain an adequate FRC. Newborns with apnea or severe respiratory compromise may benefit from an initial SI, but are also dependent on a rate and PPV. Unfortunately, knowing the optimal peak inspiratory pressure during PPV to produce an appropriate $V_{T}$ and FRC presents a challenge as $V_{T}$ is dependent on various factors such as (1) spontaneous breathing activity of the infant, (2) lung compliance and resistance, (3) the amount of lung liquid and how quickly it is absorbed, and (4) the inflation-time used [52]. Moreover, during bag-mask ventilation, mask leak can further compromise adequate FRC and $V_{T}$ delivery [53-56]. In the setting of inadequate ventilation, the most recent NRP guidelines devised the MR SOPA acronym (Figure 1) to remind resuscitators to initiate ventilation corrective steps: $M$ (mask adjustment), $R$ (reposition airway), S (suction mouth and nose), O (open mouth), P (pressure increase), A (alternate airway) [5]. 


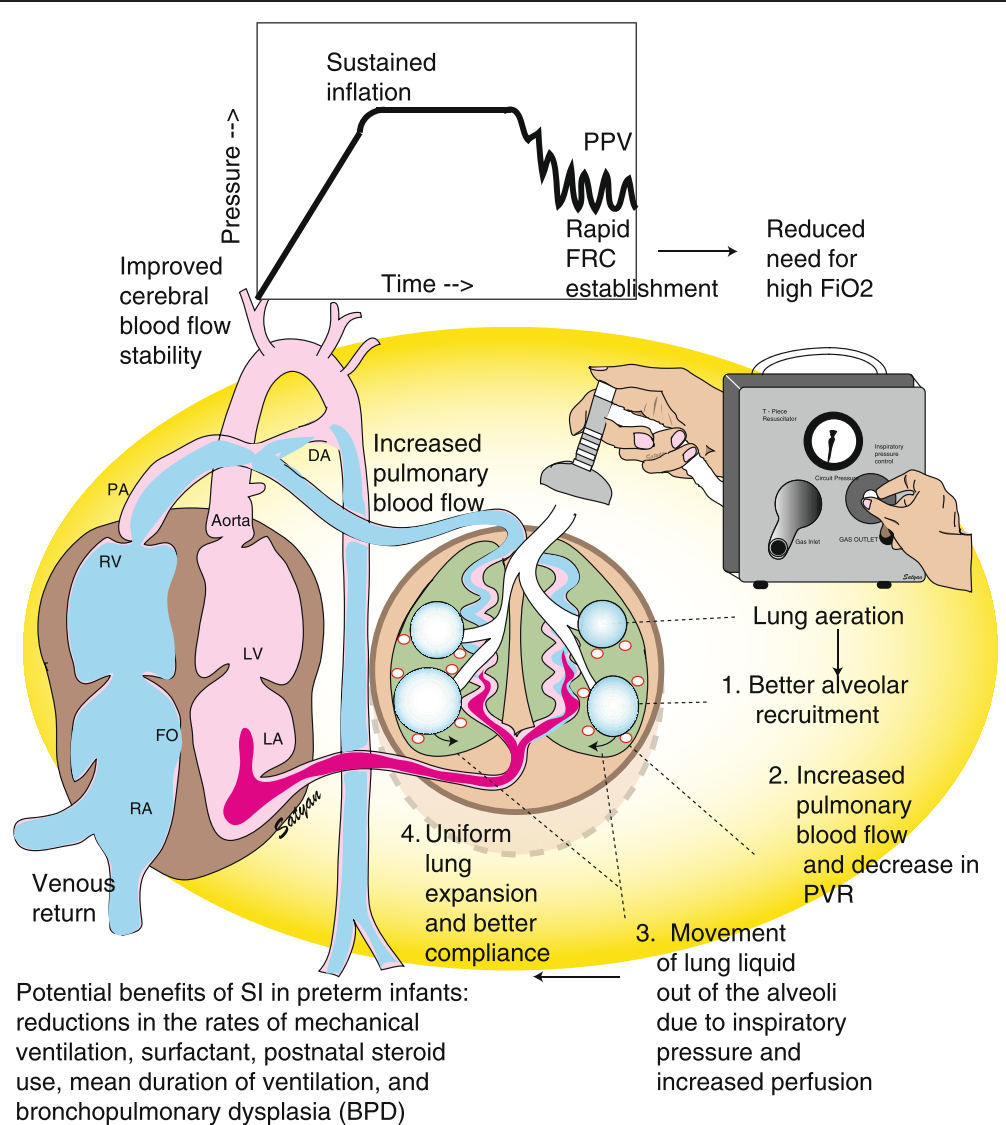

Figure 4 Sustained inflation (SI) in neonatal resuscitation. The fluid filled lung of a newborn infant potentially benefits from prolonged inspiratory time and pressure of SI to facilitate (1) alveolar recruitment, (2) increased pulmonary blood flow and decreased pulmonary vascular resistance, (3) movement of lung liquid out of the alveoli, and (4) uniform lung expansion and better compliance. Rapid establishment in FRC results in improved cerebral blood flow stability and reduced need for $\mathrm{FiO}_{2}$. DA ductus arteriosus, $\mathrm{FiO}_{2}$ fraction of inspired oxygen, $\mathrm{FRC}$ functional residual capacity, LA left atrium, LV left ventricle, PA pulmonary artery, PPV positive pressure ventilation, PVR pulmonary vascular resistance, RA right atrium, RV right ventricle. Copyright Satyan Lakshminrusimha.

Although each ventilation device has its advantages and disadvantages, there is currently no recommendation to guide healthcare providers on the choice of apparatus to use [57,58]. A recent comprehensive, international cluster-randomized crossover study in newborns $\geq 26$ weeks gestation has shown a significant reduction in the number of infants intubated in the T-piece resuscitator group as compared to the selfinflating bag group (17\% vs 26\%) [59]. A post hoc analysis of very low birth weight infants from this study has revealed that infants in the T-piece resuscitator group reaching a $H R>100 / \mathrm{min}$ by two minutes are less likely to be intubated and less likely to develop BPD [60]. Albeit the disadvantage of self-inflating bags to provide CPAP and PEEP [42], critical in establishing and maintaining an FRC [45], successful ventilation will be dependent on the expertise of providers in using any device available to them. The emphasis should, therefore, be given to adequate training in the use of these devices [5,54].

\section{Noninvasive support in the delivery room}

Three extensive randomized controlled trials (COIN, SUPPORT and Delivery Room Management Trial) have evaluated the use of CPAP in comparison with immediate intubation and surfactant, showing a trend towards decreased rates of death/BPD and a reduced need for surfactant [61-63]. Two meta-analyses have demonstrated that one additional infant could survive to 36 weeks without BPD for every 25 babies treated with nasal CPAP in the delivery room rather than being intubated [64] and that strategies aimed at avoiding mechanical ventilation have a small but significant beneficial impact on preventing BPD with a NNT of 35 [65]. Following this evidence, in January of 2014, the American Academy of Pediatrics Committee on Fetus and Newborn published a policy statement concluding that "the early use of CPAP with subsequent selective surfactant administration in extremely preterm infants results in lower rates of $\mathrm{BPD} /$ death compared with treatment with prophylactic or early surfactant therapy." [66]. An editorial by Foglia et al. 
provides an explanation for the modest effects observed with a noninvasive delivery room ventilation strategy [60]. Although the above-mentioned trials were designed to compare CPAP vs routine intubation and surfactant administration, many premature infants require PPV during their initial stabilization after birth. Due to the difficulty in providing adequate mask-ventilation, many infants will require tracheal intubation to achieve effective ventilation.

\section{Oxygen}

Mitochondria provide energy to the living organisms through aerobic metabolism. During this process, mitochondria produce reactive oxygen species as a byproduct that leads to formation of chemical species including highly reactive-free radicals capable of causing functional and structural damage to other cell components. The immature antioxidant defense in newborn and premature infants predisposes this population to higher oxidative stress [67] and cell damage [68]. Beyond the biochemical derangement caused by oxygen toxicity, clinical and animal studies comparing the use of room-air resuscitation to $100 \%$ oxygen in asphyxiated subjects have shown an increased time to first cry and a delay in spontaneous respiratory pattern $[69,70]$, implying that pure oxygen may inhibit respiratory activity in newborn infants. Studies in lambs indicate that the decrease in pulmonary vascular resistance at birth can be achieved effectively with optimal ventilation of the lungs with $21 \%$ oxygen in control [71], asphyxiated [72], and lambs with pulmonary hypertension and pulmonary arterial remodeling [73]. The understanding of the significance of oxidative stress that emerged during the 1980s and 1990s has contributed to an increased attention to oxygenation levels in newborn babies both in and beyond the delivery room [74]. Since 2010, the new ILCOR guidelines recommend starting term or near-term newborns needing ventilation on air rather than pure oxygen [24]. However, little data exist regarding oxygen supplementation in the period immediately after resuscitation. Though the effects of hypoxemia immediately following birth remain largely unknown, there is considerable evidence pointing to serious deleterious effects of hyperoxemia in the first few hours of life [10,75-77].

\section{Asphyxia and hyperoxemia}

A recent retrospective analysis of newborn infants with severe perinatal acidemia finds an association between hyperoxemia during the first hour of life and development of hypoxic-ischemic encephalopathy (HIE) [77]. Out of the 120 newborns who had qualified for whole body hypothermia for $\mathrm{HIE}, 30 \%$ had a $\mathrm{PaO}_{2}>100 \mathrm{~mm}$ $\mathrm{Hg}$ during the first hour of their life and were classified as hyperoxemic. The authors proposed that hyperoxemia was associated with a four-fold increased risk of moderate to severe HIE and that the incidence of HIE is directly related to the degree of hyperoxemia. MRI changes compatible with HIE are found in 79\% of hyperoxemic newborns and in 33\% of normoxic newborns [74]. These results support previous studies that have reported increased risk of poor outcome in babies with hyperoxemia $(\mathrm{PaO} 2>200 \mathrm{mmHg})$ in the first 2 hours of their life [75]. There is also a significant association between fraction of inspired $\mathrm{O}_{2}\left(\mathrm{FiO}_{2}\right)$ during the first 6 hours and the adverse effects in cooled babies who had already developed HIE [76]. A recent systematic review and meta-analysis studying the effects of low and high $\mathrm{FiO}_{2}$ during the resuscitation of 677 newborn babies $\leq 32$ weeks gestation has shown that reduced mortality approached a significant value when a low $\mathrm{FiO}_{2}$ (0.21-0.30) is used, compared to a high $\mathrm{FiO}_{2}(0.60-1.0)$ [10]. Healthcare providers need to be aware of the deleterious effects of hyperoxemia, avoid hyperoxygenation and attempt to target normoxia.

The current guidelines recommend supplemental oxygen during CCs. The optimal inspired oxygen during $\mathrm{CCs}$ in a neonate with asphyxia and bradycardia or cardiac arrest is not known.

\section{Chest compressions}

The need for CCs is infrequent in neonatal resuscitation, with an estimated occurrence of $0.08 \%$ for near-term and term deliveries and a higher frequency $(2-10 \%)$ in preterm infants $[78,79]$. Among the survivors who require CCs at birth, many suffer from detrimental neurologic deficits $[80,81]$. In the event of severe bradycardia or cardiac arrest, CCs are provided to re-establish coronary perfusion pressure (CPP), to revive the heart and achieve return of spontaneous circulation, as well as to provide blood flow to the body. There is still a lack of scientific evidence to support the current recommendations for CCs during neonatal resuscitation. The current guidelines are based on literature published on animal, pediatric and adult research, as well as physiological feasibility and expert opinion [79]. Optimizing the compression to ventilation $(\mathrm{CV})$ ratio, the timing and heart rate nadir to determine when to initiate CCs, and the timing, route of administration and choice of resuscitative drugs still remain to be addressed.

\section{Cardiac and thoracic pump theory}

The mechanism by which CCs achieve cardiac output can be explained by two theories (Figure 5) [82]: (1) in the thoracic pump theory, external CCs produce an elevation in intrathoracic pressure that is transmitted to the thoracic vasculature. Pressure in intrathoracic arteries is then transmitted to extrathoracic arteries, but jugular venous valves and possible collapse of veins at the thoracic inlet may prevent full transmission of intrathoracic pressure to the extrathoracic veins. This uneven 


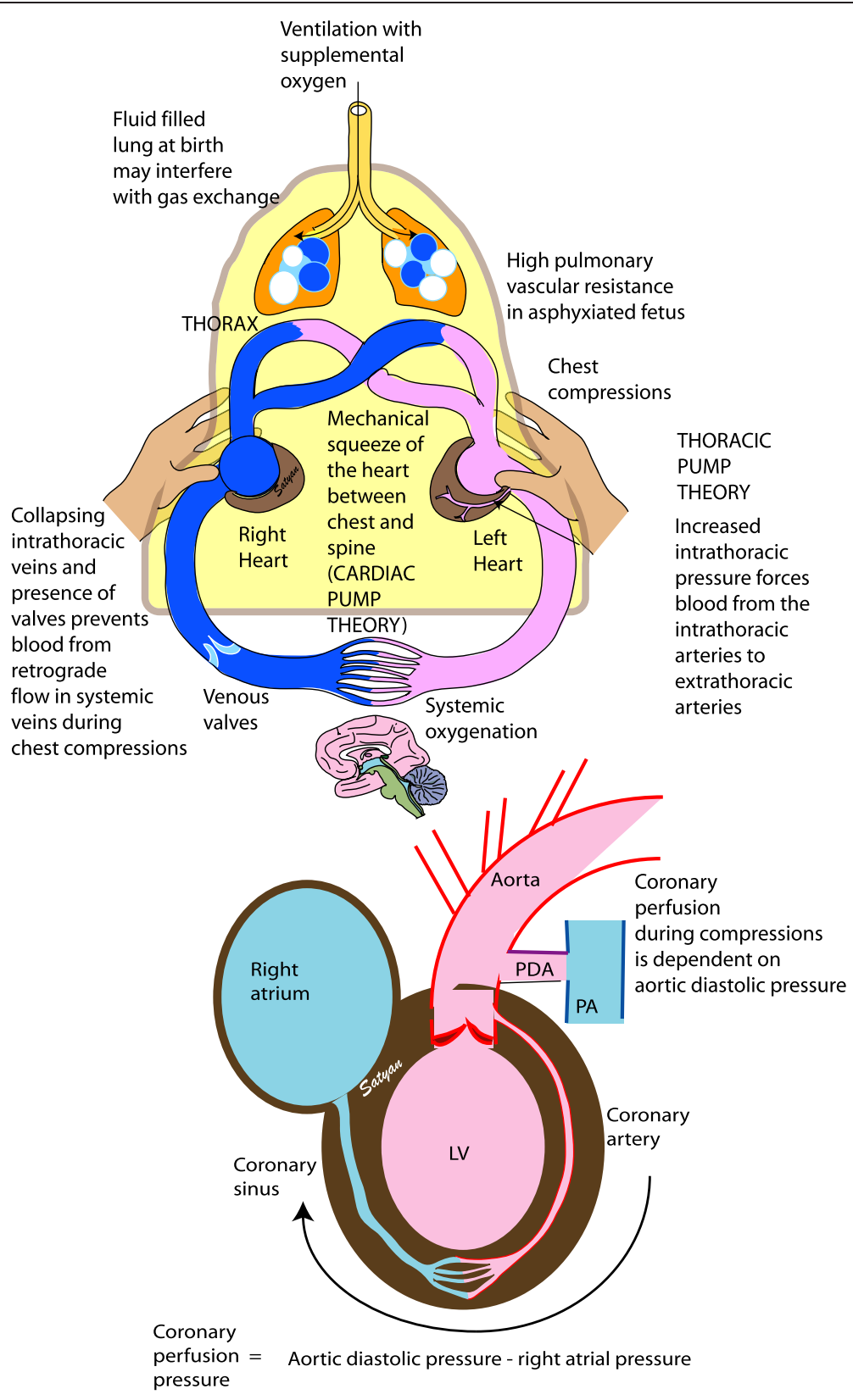

Figure $\mathbf{5}$ Chest compressions (CC). During CCs, the extrinsic pressure on the sternum squeezes the heart against the spine leading to antegrade blood flow (cardiac pump theory). During ventilation, generation of increased thoracic pressure results in arterial blood flow from the thorax because intrathoracic pressure exceeds extrathoracic vascular pressure (thoracic pump theory). Flow is restricted to the arterial-to-venous direction because of collapse of veins at the thoracic inlet and venous valves that prevent retrograde flow. Coronary perfusion pressure (CPP) is a key determinant in return of spontaneous resuscitation and is dependent on aortic diastolic and right atrial pressure. In the presence of a PDA, CCs may be less effective as aortic diastolic pressure may be decreased with blood shunting from the aorta into the pulmonary artery, thus decreasing CPP. LV left ventricle, PA pulmonary artery, PDA patent ductus arteriosus. Copyright Satyan Lakshminrusimha.

transmission of pressures between the arterial and venous vasculature provides a gradient for antegrade blood flow during CCs; (2) the cardiac pump theory postulates that blood flows through the mechanical squeeze of the heart between the sternum and the spine. The predominant mechanism in the newborn is unclear. In the infant's more compliant chest, the cardiac pump theory may contribute to blood flow to a greater extent. However, in the setting of sustained inflations and increased intrathoracic pressure, there may be an increased effect through the thoracic pump theory. This effect may partly explain the outcomes in two studies conducted on 
an asphyxiated piglet model. In the first study, when comparing continuous CCs with asynchronous ventilation to 3:1 CV resuscitation, no difference in return of spontaneous circulation was appreciated [83]. In the second study, when continuous CCs were given during SIs, there was a significant reduction in time to return of spontaneous circulation as compared to the $3: 1 \mathrm{CV}$ group [84]. We speculate that by maintaining an increased thoracic pressure with SI, the infant's chest compliance is decreased and may enhance antegrade blood flow through the thoracic pump mechanism. In addition, with increased pulmonary flow during SI, more blood returns to the heart through the pulmonary veins, effectively increasing ventricle filling volume and thus increasing cardiac output during compressions.

\section{Cardiac arrest in the neonate}

In contrast to adults, where arrhythmias lead to an abrupt cessation in cardiac output in the setting of well-oxygenated blood, neonatal asystole arises from profound bradycardia as a result of oxygen depletion, carbon dioxide accumulation and increasing lactic acidosis secondary to asphyxia. Oxygen levels remain relatively high in cases of cardiac arrest secondary to arrhythmias. There is a growing body of evidence that under these conditions continuous CCs are associated with improved survival [85-87] and animal models using this approach show improved neurologic outcomes [80-90]. In the asphyxiated neonate with cardiac arrest, due to severe hypoxemia and hypercarbia, ventilation remains critical in establishing return of spontaneous circulation and exclusive CCs in asphyxiated piglet models has not shown to be effective in achieving return of spontaneous circulation [91,92].

\section{Chest compression technique and compression to ventilation ratios}

Animal and manikin studies have demonstrated that the two-thumb technique provide higher systolic and mean arterial blood pressures, more consistent depth of compressions, improved positioning and less fatigue compared with the two-finger method [93-96]. Even in the setting for emergent umbilical line placement, the provider can continue the two-thumb technique from the head of the bed to leave access at the umbilicus.

Ventilation of the lungs is a critical component of neonatal resuscitation. However, in the presence of extreme bradycardia or cardiac arrest, pulmonary blood flow cannot be sustained and gas exchange does not occur with ventilation alone. Although a combination of PPV and $\mathrm{CCs}$ are required for effective resuscitation, the optimal $\mathrm{CV}$ ratio remains to be determined. The current 3:1 CV ratio recommended by NRP is an expert consensus, attempting to match the heart and respiratory rates of the newborn. Animal models and manikin studies have compared different compression to ventilation ratios [97-99]. Although a 15:2 CV ratio in an asphyxiated piglet cardiac arrest model has shown statistically higher diastolic pressures, no improvement in return of spontaneous circulation has been achieved without epinephrine [98]. In contrast, a newborn manikin model has shown more consistent depth of compression with a 3:1 CV ratio as compared to 5:1 or 15:2 ratios [99]. The results of a recent study in asphyxiated term piglets comparing the current recommended 3:1 CV resuscitation to continuous $\mathrm{CCs}$ with asynchronous ventilation does not reveal a significant difference in the time to achieve return of spontaneous circulation and hemodynamic parameters. However, using the same animal model, the authors have shown significantly improved return of spontaneous circulation with better hemodynamic recovery when continuous CCs were given during SIs as compared to the conventional 3:1 CV group [84]. A clinical study comparing CC during SI to $3: 1 \mathrm{CV}$ is currently in progress (ClinicalTrials.gov Identifier: NCT02083705).

\section{Drugs in the delivery room}

Epinephrine has been used in modern cardiopulmonary resuscitation (CPR) since the 1960s. In spite of extensive research on vasopressor use, there is an ongoing controversy regarding the long-term benefits of vasopressor use with possible worse neurologic outcomes as reported in the literature on adult patients [100,101]. Owing to the infrequent use of medications during neonatal resuscitation $(<0.1 \%$ of live-born deliveries), there is a lack of rigorous scientific evidence for a positive effect of medication in newborns. The recommendations are based on research conducted on animals and adults. Therefore, the role of medications in newborn resuscitation including appropriate dosing, order and route of administration remains controversial [11].

\section{Epinephrine in neonatal resuscitation}

Epinephrine is a catecholamine with inotropic (increase cardiac contractility), lusitropic (myocardial relaxation), chronotropic (increase heart rate) and vasoconstrictor properties. The vasoconstrictor properties mediated by $\alpha$-adrenergic receptors are primarily responsible for its effectiveness in CPR [102]. Administration of epinephrine is believed to induce intense peripheral vasoconstriction resulting in elevated systemic vascular resistance and an increase in coronary perfusion pressure to improve coronary flow [103]. Animal studies indicate that CCs alone are inadequate for increasing cerebral blood flow and that the administration of epinephrine results in a higher probability for return of spontaneous circulation $[98,104]$.

Redding et al. have demonstrated for the first time a significant improvement in using $1 \mathrm{mg}$ intravenous (IV) epinephrine $(0.1 \mathrm{mg} / \mathrm{kg})$ in asphyxia-induced cardiac 
arrest in mongrel dogs to achieve return of spontaneous circulation [105]. Human studies following this report do not account for the weight difference and demonstrate return of spontaneous circulation with $1 \mathrm{mg}$ IV epinephrine ( $\sim 0.01-0.015 \mathrm{mg} / \mathrm{kg})$, which is then extrapolated to neonatal and pediatric patients with dose ranges of $0.01-0.03 \mathrm{mg} / \mathrm{kg}$ [11]. The use of high dose IV epinephrine $(0.2 \mathrm{mg} / \mathrm{kg})$ in a pediatric swine model has shown to be associated with severe tachycardia, hypertension and higher mortality in the immediate post-resuscitation period [106]. In neonatal lambs, the use of high dose IV epinephrine $(0.1 \mathrm{mg} / \mathrm{kg})$ results in reduced stroke volume and cardiac output [107]. In addition there is no evidence to support the use of high dose intravenous epinephrine in adults [100].

\section{Endotracheal epinephrine}

In a retrospective review, a dose of $0.01-0.03 \mathrm{mg} / \mathrm{kg}$ has been first administered by the endotracheal route in $94 \%$ of infants requiring epinephrine. With this dose only $32 \%$ achieved return of spontaneous circulation. Following a repeat IV epinephrine at the same dose, $77 \%$ of the initial non-responders have achieved return of spontaneous circulation. The high frequency of initial endotracheal epinephrine use makes it critical that the recommended dose for endotracheal epinephrine be as effective as possible. Neonatal piglets (2-4 days of age) with induced ventricular fibrillation were resuscitated with $0.01 \mathrm{mg} / \mathrm{kg}$ epinephrine or placebo administered into the endotracheal tube, femoral vein, or right atrium. Right atrial and femoral venous administration resulted in optimal peak levels by 1-2 min after administration. No increase in plasma epinephrine concentration was observed after endotracheal epinephrine administration $(0.01 \mathrm{mg} / \mathrm{kg})$ [108]. These results confirm that low dose epinephrine by the ETT is not effective.

Barber et al have compared low dose endotracheal epinephrine $(0.03 \mathrm{mg} / \mathrm{kg})$ to high dose endotracheal epinephrine $(0.07 \mathrm{mg} / \mathrm{kg})$ and IV epinephrine $(0.01 \mathrm{mg} / \mathrm{kg})$ in asphyxiated piglets [109]. High dose endotracheal epinephrine is associated with $89 \%$ return of spontaneous circulation within $15 \mathrm{~min}$ after asystole and all of these piglets were alive 30 minutes after return of spontaneous circulation. When compared to IV epinephrine, high dose endotracheal epinephrine does not cause increased rebound hypertension or tachycardia. If IV access is not readily available, high dose endotracheal epinephrine $(0.03$ to $0.1 \mathrm{mg} / \mathrm{kg})$ is a reasonable alternative without detrimental effects.

In addition, newborns in the delivery room have unique physiology consisting of fluid-filled alveoli at birth, an open ductus arteriosus and venosus, and the need to transition from fetal to newborn circulation $[11,110]$. In the presence of asphyxia and acidosis, elevated pulmonary vascular resistance may limit blood flow to the lungs
(Figure 6). Studies done in postnatal models such as 1-3 day old piglets that have completed transition may not accurately represent the transitional physiology observed in the delivery room. These physiologic concerns may be partially compensated by using a higher dose of epinephrine via the endotracheal route to compensate for dilution by fetal lung liquid (Figure 6). Lucas et al. have shown that epinephrine levels in pulmonary venous blood increase significantly with hypoxia-associated reduction in pulmonary blood flow [111]. This finding suggests that low pulmonary blood flow may not be the limiting factor for absorption of endotracheal epinephrine. Future studies need to investigate the optimal epinephrine dose to be administered through the endotracheal tube. Early administration of the optimal epinephrine dose by the endotracheal route may promote aortic diastolic pressure, coronary perfusion pressure and hasten return of spontaneous circulation.

Alternate medications such as vasopressin are currently being investigated. Unlike epinephrine, vasopressin is not a direct myocardial stimulant and does not significantly increase myocardial oxygen demand. A recent study in asphyxiated neonatal piglets has shown improved survival, lower post-resuscitation troponin, and less hemodynamic compromise in piglets resuscitated with vasopressin when compared to epinephrine [112]. Though vasopressin has not been shown to be superior to epinephrine in adult CPR [113], its effect in neonatal resuscitation deserves further studies.

\section{Resuscitation in resource-limited settings}

Among the approximately 4 million neonatal deaths annually around the world, up to $70 \%$ occur within the first day of life and 99\% take place in resource-poor settings [114]. Strategies for prevention of adverse perinatal outcomes in a resource limited setting can be divided into three categories: (1) primary prevention of the insult by adequate fetal monitoring coupled with timely obstetric intervention and referral by traditional birth attendants, (2) secondary prevention after the insult by immediate basic stabilization/resuscitation such as PPV with room air to an infant with respiratory depression, and (3) tertiary prevention of complications in the baby by adequate post-resuscitation care [4]. The 'Helping Babies Breathe ${ }^{\circledast}$ (HBB) program focuses on evidencebased educational programs to teach neonatal resuscitation techniques to resource-limited areas and is being promoted by the AAP, WHO, USAID and the National Institute of Child Health and Human Development (NICHD) [115]. The objective of this program is to train birth attendants in developing countries on the essential skills of newborn resuscitation. In Tanzania, following $\mathrm{HBB}$ training in referral and regional hospitals, an increase in babies being stimulated from $44 \%$ to $88 \%$ 


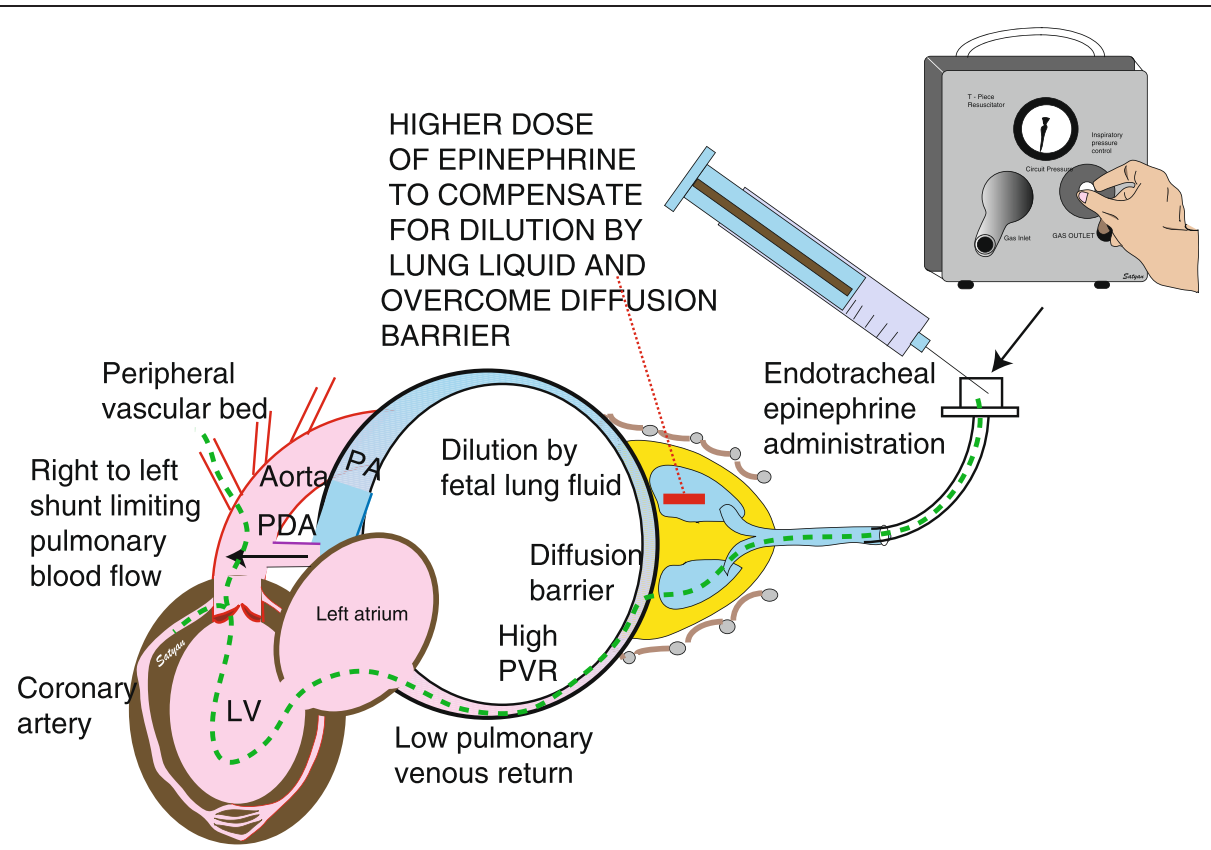

Figure 6 Endotracheal epinephrine. Theoretical concerns regarding endotracheal epinephrine administration in perinatal asphyxia. Asphyxia and acidosis lead to a decrease in systemic vascular resistance by dilating the peripheral vascular bed. Coronary perfusion pressure is low. High fetal pulmonary vascular resistance may lead to right to left shunting at the PDA level limiting pulmonary blood flow. Presence of fetal lung liquid may dilute tracheal epinephrine and absorption may be limited by low pulmonary blood flow. The proposed path of intratracheal epinephrine is shown by a hyphenated green line. A higher dose of endotracheal epinephrine may compensate and achieve higher plasma levels. LV left ventricle, PA pulmonary artery, PDA patent ductus arteriosus, PVR pulmonary vascular resistence. Copyright Satyan Lakshminrusimha.

resulted in a decrease in bag-mask ventilation [116]. In addition, delayed/physiological cord clamping after the onset of breathing has been shown to reduce the incidence of death/hospital admission in a rural Tanzanian center [117]. Such simple interventions will assist the majority of babies and reduce rates of neonatal mortality.

\section{Conclusions}

Over the past few decades, a tremendous amount of knowledge has been gained in the field of neonatal resuscitation. We have also identified gaps in knowledge on how to best approach and treat newborns in need of aggressive resuscitation. The emphasis should lie on optimizing ventilation, while avoiding lung injury and hyperoxemia. Though sustained inflations may prove to be beneficial, the means by which to best provide positive pressure ventilation to establish and maintain a functional residual capacity, how to best assess ventilation and how to decrease mask leak remains to be determined. In the rare instance that chest compressions and medications are needed to achieve effective return of spontaneous circulation, the optimal compression to ventilation ratio, the timing, route, dose and type of vasopressor still needs to be studied. With the advancement of science and the development of technology, it is expected that healthcare providers will have more reliable tools to reduce the rates of newborn mortality.
In addition to technological advances, the need for further research evaluating strategies for education, dissemination of knowledge and appropriate interventions for resource-limited settings is important. Simple interventions such as delayed/physiological cord clamping, drying and stimulating newborns, and bag-mask ventilation along with programs such as 'Helping Babies Breathe ${ }^{\otimes}$ ' will have a significant impact on reducing mortality and morbidity secondary to birth asphyxia worldwide.

\section{Abbreviations}

AAP: American Academy of Pediatrics; ACOG: American Congress of Obstetricians and Gynecologists; AHA: American Heart Association; BPD: Bronchopulmonary dysplasia; CCs: Chest compressions; CPAP: Continuous positive airway pressure; CPP: Coronary perfusion pressure; CPR: Cardiopulmonary resuscitation; CV ratio: Compression to ventilation ratio; FRC: Functional residual capacity; HBB: Helping Babies Breathe ${ }^{\otimes \prime}$; HIE: Hypoxic-ischemic encephalopathy; ILCOR: International Liaison Committee on Resuscitation; IV: Intravenous; IVC: Inferior venous cava; MAS: Meconium aspiration syndrome; MSAF: Meconium stained amniotic fluid; NNT: Number needed to treat; NRP: Neonatal Resuscitation Program; PEEP: Positive end-expiratory pressure; PPV: Positive pressure ventilation; RCT: Randomized controlled trial; SI: Sustained inflation; USAID: United States Agency for International Development; $V_{T}$ : Tidal volume; WHO: World Health Organization.

\section{Competing interest}

The authors declare that they have no competing interests. 


\section{Authors' contriubtions}

PV made contributions to the conception, acquisition of data and was involved in drafting the manuscript. BM contributed to the section on chest compression and critically revising the manuscript. SL substantially contributed to writing the introduction, completed the section on meconium aspiration and critically revised the manuscript. SL designed all figures in the manuscript. All authors read and approved the final manuscript.

\section{Authors' information}

$\mathrm{PV}$ is a fellow in neonatology, BM is an assistant professor in neonatology, and $S L$ is professor of pediatrics and chief, division of neonatology at Women and Children's Hospital of Buffalo, 219 Bryant Street, NY 14222, USA.

\section{Acknowledgment}

$\mathrm{SL}$ is funded by grant 1R01HD072929-0.

Received: 24 September 2014 Accepted: 3 November 2014

Published online: 22 January 2015

\section{References}

1. Black RE, Cousens S, Johnson HL, Lawn JE, Rudan I, Bassani DG, Jha P, Campbell H, Walker CF, Cibulskis R, Eisele T, Liu L, Mathers C, Child Health Epidemiology Reference Group of, W. H. O. Unicef: Global, regional, and national causes of child mortality in 2008: a systematic analysis. Lancet 2010, 375(9730):1969-1987.

2. Wyllie J, Perlman JM, Kattwinkel J, Atkins DL, Chameides L, Goldsmith JP, Guinsburg R, Hazinski MF, Morley C, Richmond S, Simon WM, Singhal N, Szyld E, Tamura M, Velaphi S. Neonatal Resuscitation Chapter Collaborators: Part 11: neonatal resuscitation: 2010 international consensus on cardiopulmonary resuscitation and emergency cardiovascular care science with treatment recommendations. Resuscitation 2010, 81 Suppl 1:e260-e287

3. Thio M, van Kempen $L$, Rafferty AR, Bhatia R, Dawson JA, Davis PG Neonatal resuscitation in resource-limited settings: titrating oxygen delivery without an oxygen blender. J Pediatr 2014, 165(2):256-260. e251.

4. Ersdal $\mathrm{HL}$, Singhal $\mathrm{N}$ : Resuscitation in resource-limited settings. Semin Fetal Neonatal Med 2013, 18(6):373-378.

5. Kattwinkel J: Textbook of Neonatal Resuscitation. 6th edition. Elk Grove Village IL: American Academy of Pediatrics; 2011.

6. Perlman J, Kattwinkel J, Wyllie J, Guinsburg R, Velaphi S, Group NSftNITF: Neonatal resuscitation: in pursuit of evidence gaps in knowledge. Resuscitation 2012, 83(5):545-550.

7. Fraser WD, Hofmeyr J, Lede R, Faron G, Alexander S, Goffinet F, Ohlsson A, Goulet C, Turcot-Lemay L, Prendiville W, Marcoux S, Laperriere L, Roy C, Petrou S, Xu HR, Wei B: Amnioinfusion for the prevention of the meconium aspiration syndrome. N Engl J Med 2005, 353(9):909-917.

8. Vain NE, Szyld EG, Prudent LM, Wiswell TE, Aguilar AM, Vivas NI: Oropharyngeal and nasopharyngeal suctioning of meconium-stained neonates before delivery of their shoulders: multicentre, randomised controlled trial. Lancet 2004, 364(9434):597-602.

9. Wiswell TE, Gannon CM, Jacob J, Goldsmith L, Szyld E, Weiss K, Schutzman D, Cleary GM, Filipov P, Kurlat I, Caballero CL, Abassi S, Sprague D, Oltorf C Padula M: Delivery room management of the apparently vigorous meconium-stained neonate: results of the multicenter, international collaborative trial. Pediatrics 2000, 105(1 Pt 1):1-7.

10. Saugstad OD, Aune D, Aguar M, Kapadia V, Finer N, Vento M: Systematic review and meta-analysis of optimal initial fraction of oxygen levels in the delivery room at $\leq 32$ weeks. Acta Paediatr 2014, 103(7):744-751.

11. Kapadia VS, Wyckoff MH: Drugs during delivery room resuscitation-what, when and why? Semin Fetal Neonatal Med 2013, 18(6):357-361.

12. Goldsmith JP: Delivery Room Resuscitation of the Newborn. Part 1 Overview and initial Management. In: Fanaroff and Martin's NeonatalPerinatal Medicine. Volume 1, 9th edn. Edited by Martin R, Fanaroff A, Walsh MC: Philadelphia, PA: Elsevier; 2011: 449-458

13. Adamson S, Myatt L, Byrne B: Regulation of Umbilical Blood Flow. In: Fetal and Neonatal Physiology. Volume 1, 4th edn. Edited by Polin R, Fox W, Abman S: Philadelphia, PA: Elsevier; 2011: 827-837.

14. Raju TN, Singhal N: Optimal timing for clamping the umbilical cord after birth. Clin Perinatol 2012, 39(4):889-900.

15. McAdams RM: Time to implement delayed cord clamping. Obstet Gynecol 2014, 123(3):549-552.
16. Rabe H, Reynolds G, Diaz-Rossello J: A systematic review and meta-analysis of a brief delay in clamping the umbilical cord of preterm infants. Neonatology 2008, 93(2):138-144.

17. Sommers R, Stonestreet BS, Oh W, Laptook A, Yanowitz TD, Raker C, Mercer $\mathrm{J}$ : Hemodynamic effects of delayed cord clamping in premature infants. Pediatrics 2012, 129(3):e667-e672.

18. Hutton EK, Hassan ES: Late vs early clamping of the umbilical cord in full-term neonates: systematic review and meta-analysis of controlled trials. JAMA 2007, 297(11):1241-1252.

19. van Rheenen $\mathrm{P}$, Brabin BJ: Late umbilical cord-clamping as an intervention for reducing iron deficiency anaemia in term infants in developing and industrialised countries: a systematic review. Ann Trop Paediatr 2004, 24(1):3-16.

20. Rabe H, Diaz-Rossello JL, Duley L, Dowswell T: Effect of timing of umbilical cord clamping and other strategies to influence placental transfusion at preterm birth on maternal and infant outcomes. Cochrane Database Syst Rev 2012, 8, CD003248.

21. McDonald SJ, Middleton P, Dowswell T, Morris PS: Effect of timing of umbilical cord clamping of term infants on maternal and neonatal outcomes. Cochrane Database Syst Rev 2013, 7, CD004074.

22. Andersson O, Hellström-Westas L, Andersson D, Domellöf M: Effect of delayed versus early umbilical cord clamping on neonatal outcomes and iron status at 4 months: a randomised controlled trial. BMJ 2011, 343:d7157.

23. Bhatt S, Alison BJ, Wallace EM, Crossley KJ, Gill AW, Kluckow M, te Pas AB, Morley CJ, Polglase GR, Hooper SB: Delaying cord clamping until ventilation onset improves cardiovascular function at birth in preterm lambs. J Physiol 2013, 591(Pt 8):2113-2126.

24. Perlman JM, Wyllie J, Kattwinkel J, Atkins DL, Chameides L, Goldsmith JP, Guinsburg R, Hazinski MF, Morley C, Richmond S, Simon WM, Singhal N, Szyld E, Tamura M, Velaphi S. Neonatal Resuscitation Chapter Collaborators: Part 11: neonatal resuscitation: 2010 international consensus on cardiopulmonary resuscitation and emergency cardiovascular care science with treatment recommendations. Circulation 2010, 122(16 Suppl 2):S516-S538.

25. Committee on Obstetric Practice AeCoOaG: Committee opinion No.543: timing of umbilical cord clamping after birth. Obstet Gynecol 2012 120(6):1522-1526

26. Miller SS, Lee HC, Gould JB: Hypothermia in very low birth weight infants: distribution, risk factors and outcomes. J Perinato/ 2011, 31(Suppl 1):S49-S56.

27. Chitty $\mathrm{H}$, Wyllie J: Importance of maintaining the newly born temperature in the normal range from delivery to admission. Semin Fetal Neonatal Med 2013, 18(6):362-368

28. Richmond S, Wyllie J: European Resuscitation Council Guidelines for Resuscitation 2010 Section 7. Resuscitation of babies at birth Resuscitation 2010, 81(10):1389-1399.

29. Bergman NJ, Linley LL, Fawcus SR: Randomized controlled trial of skin-toskin contact from birth versus conventional incubator for physiological stabilization in 1200- to 2199-gram newborns. Acta Paediatr 2004, 93(6):779-785

30. Katheria AC, Leone TA, Woelkers D, Garey DM, Rich W, Finer NN: The effects of umbilical cord milking on hemodynamics and neonatal outcomes in premature neonates. J Pediatr 2014, 164(5):1045-1050. e1041.

31. Bacsik RD: Meconium aspiration syndrome. Pediatr Clin North Am 1977, 24(3):463-479.

32. Dillard RG: Neonatal tracheal aspiration of meconium-stained infants. J Pediatr 1977, 90(1):163-164.

33. Fox WW, Gutsche BB, DeVore JS: A delivery room approach to the meconium aspiration syndrome (MAS). Immediate intubation, endotracheal suction, and oxygen administration can reduce morbidity and mortality. Clin Pediatr (Phila) 1977, 16(4):325-328.

34. Goodlin RC: Suppression of fetal breathing to prevent aspiration of meconium. Obstet Gynecol 1970, 36(6):944-947.

35. Goodlin RC: The prevention of meconium aspiration in labor using amnioinfusion. Obstet Gynecol 1989, 74(3 Pt 1):430-431.

36. Aub-Shaweesh JM: Respiratory Disorders in Preterm and Term Infants. In Fanaroff and Martin's Neonatal Perinatal Medicine. Volume 2. 9th edition. Edited by Martin RJ, Fanaroff AA, Walsh MC. St. Louis, MO: Elsevier; 2010:1157-1160

37. Al Takroni AM, Parvathi CK, Mendis KB, Hassan S, Reddy I, Kudair HA: Selective tracheal suctioning to prevent meconium aspiration syndrome. Int J Gynaecol Obstet 1998, 63(3):259-263. 
38. Guglani L, Lakshminrusimha S, Ryan RM: Transient tachypnea of the newborn. Pediatr Rev 2008, 29(11):e59-e65.

39. Carlton D: Regulation of Liquid Secretion and Absorption by the Fetal and Neonatal Lung. In: Fetal and Neonatal Physiology. Volume 1, 4th edn. Edited by Polin R, Fox W, Abman S: Philadelphia, PA: Elsevier; 2011: 907-919.

40. Saugstad OD: Physiology of Resuscitation. In: Fetal and Neonatal Physiology. Volume 1, edn. Edited by Polin R, Fox W, Abman S: Philadelphia, PA: Elsevier; 2011: 846-853.

41. Vyas H, Field D, Milner AD, Hopkin IE: Determinants of the first inspiratory volume and functional residual capacity at birth. Pediatr Pulmonol 1986, 2(4):189-193.

42. Te Pas AB, Morley C: Delivery Room Resuscitation of the Newbon. Part 2 - Role of Positive Pressure Ventilation in Neonatal Resuscitation. In: Fanaroff and Martin's Neonatal-Perinatal Medicine. Volume 1, ninth edn. Edited by Martin R, Fanaroff A, Walsh MC. St. Louis, Missouri: Elsevier; 2011: 458-468

43. te Pas AB, Davis PG, Kamlin CO, Dawson J, O'Donnell CP, Morley CJ: Spontaneous breathing patterns of very preterm infants treated with continuous positive airway pressure at birth. Pediatr Res 2008 64(3):281-285.

44. te Pas AB, Wong C, Kamlin CO, Dawson JA, Morley CJ, Davis PG: Breathing patterns in preterm and term infants immediately after birth. Pediatr Res 2009, 65(3):352-356.

45. te Pas AB, Siew M, Wallace MJ, Kitchen MJ, Fouras A, Lewis RA, Yagi N, Uesugi K, Donath S, Davis PG, Morley CJ, Hooper, SB: Effect of sustained inflation length on establishing functional residual capacity at birth in ventilated premature rabbits. Pediatr Res 2009, 66(3):295-300.

46. Sobotka KS, Hooper SB, Allison BJ, Te Pas AB, Davis PG, Morley CJ, Moss TJ: An initial sustained inflation improves the respiratory and cardiovascular transition at birth in preterm lambs. Pediatr Res 2011, 70(1):56-60.

47. Klingenberg C, Sobotka KS, Ong T, Allison BJ, Schmölzer GM, Moss TJ, Polglase GR, Dawson JA, Davis PG, Hooper SB: Effect of sustained inflation duration; resuscitation of near-term asphyxiated lambs. Arch Dis Child Fetal Neonatal Ed 2013, 98(3):F222-F227.

48. Polglase GR, Tingay DG, Bhatia R, Berry CA, Kopotic RJ, Kopotic CP, Song Y, Szyld $E_{\text {, Jobe } A H}$, Pillow JJ: Pressure- versus volume-limited sustained inflations at resuscitation of premature newborn lambs. BMC Pediatr 2014, 14:43.

49. Lindner W, Högel J, Pohlandt F: Sustained pressure-controlled inflation or intermittent mandatory ventilation in preterm infants in the delivery room? A randomized, controlled trial on initial respiratory support via nasopharyngeal tube. Acta Paediatr 2005, 94(3):303-309.

50. Lista G, Fontana P, Castoldi F, Cavigioli F, Dani C: Does sustained lung inflation at birth improve outcome of preterm infants at risk for respiratory distress syndrome? Neonatology 2011, 99(1):45-50.

51. Dani C, Lista G, Pratesi S, Boni L, Agosti M, Biban P, Del Vecchio A, Gazzolo D, Gizzi C, Magaldi R, et al: Sustained lung inflation in the delivery room in preterm infants at high risk of respiratory distress syndrome (SLI STUDY): study protocol for a randomized controlled trial. Trials 2013, 14:67

52. O'Donnell CP, Schmölzer GM: Resuscitation of preterm infants: delivery room interventions and their effect on outcomes. Clin Perinatol 2012, 39(4):857-869.

53. Milner AD, Vyas H, Hopkin IE: Efficacy of facemask resuscitation at birth. Br Med J (Clin Res Ed) 1984, 289(6458):1563-1565.

54. Schmölzer GM, Kamlin OC, Dawson JA, te Pas AB, Morley CJ, Davis PG: Respiratory monitoring of neonatal resuscitation. Arch Dis Child Fetal Neonatal Ed 2010, 95(4):F295-F303.

55. Schmölzer GM, Morley CJ, Wong C, Dawson JA, Kamlin CO, Donath SM, Hooper SB, Davis PG: Respiratory function monitor guidance of mask ventilation in the delivery room: a feasibility study. J Pediatr 2012, 160(3):377-381. e372.

56. Wood FE, Morley CJ: Face mask ventilation-the dos and don'ts. Semin Fetal Neonatal Med 2013, 18(6):344-351.

57. Kattwinkel J, Perlman JM, Aziz K, Colby C, Fairchild K, Gallagher J, Hazinski MF, Halamek LP, Kumar P, Little G, McGowan JE, Nightengale B, Ramirez MM, Ringer S, Simon WM, Weiner GM, Wyckoff M, Zaichkin J: Part 15: neonatal resuscitation: 2010 American Heart Association Guidelines for Cardiopulmonary Resuscitation and Emergency Cardiovascular Care. Circulation 2010, 122(18 Suppl 3):S909-S919.
58. Hawkes CP, Ryan CA, Dempsey EM: Comparison of the T-piece resuscitator with other neonatal manual ventilation devices: a qualitative review. Resuscitation 2012, 83(7):797-802.

59. Szyld E, Aguilar A, Musante GA, Vain N, Prudent L, Fabres J, Carlo WA, Group DRVDT: Comparison of devices for newborn ventilation in the delivery room. J Pediatr 2014, 165(2):234-239. e233.

60. Foglia EE, Kirpalani H, DeMauro SB: Long-term respiratory morbidity in preterm infants: is noninvasive support in the delivery room the solution? J Pediatr 2014, 165(2):222-225.

61. Morley CJ, Davis PG, Doyle LW, Brion LP, Hascoet JM, Carlin JB, Investigators CT: Nasal CPAP or intubation at birth for very preterm infants. $N$ Engl J Med 2008, 358(7):700-708.

62. Finer NN, Carlo WA, Walsh MC, Rich W, Gantz MG, Laptook AR, Yoder BA, Faix RG, Das A, Poole WK, Donovan EF, Newman NS, Ambalavanan N, Frantz ID, Buchter S, Sánchez PJ, Kennedy KA, Laroia N, Poindexter BB, Cotten CM, Van Meurs KP, Duara S, Narendran V, Sood BG, O'Shea TM, Bell EF, Bhandar V, Watterberg KL, Higgins RD. SUPPORT Study Group of the Eunice Kennedy Shriver NICHD Neonatal Research Network: Early CPAP versus surfactant in extremely preterm infants. N Engl J Med 2010, 362(21):1970-1979.

63. Dunn MS, Kaempf J, de Klerk A, de Klerk R, Reilly M, Howard D, Ferrelli K, O'Conor J, Soll RF, Group VONDS: Randomized trial comparing 3 approaches to the initial respiratory management of preterm neonates. Pediatrics 2011, 128(5):e1069-e1076.

64. Schmölzer GM, Kumar M, Pichler G, Aziz K, O'Reilly M, Cheung PY: Non-invasive versus invasive respiratory support in preterm infants at birth: systematic review and meta-analysis. BMJ 2013, 347:f5980.

65. Fischer HS, Bührer C: Avoiding endotracheal ventilation to prevent bronchopulmonary dysplasia: a meta-analysis. Pediatrics 2013, 132(5):e1351-e1360

66. CoFanAAo P: Respiratory support in preterm infants at birth. Pediatrics 2014, 133(1):171-174.

67. Patel A, Lakshminrusimha S, Ryan RM, Swartz DD, Wang H, Wynn KA Kumar VH: Exposure to supplemental oxygen downregulates antioxidant enzymes and increases pulmonary arterial contractility in premature lambs. Neonatology 2009, 96(3):182-192

68. Vento M, Escobar J, Cernada M, Escrig R, Aguar M: The use and misuse of oxygen during the neonatal period. Clin Perinatol 2012, 39(1):165-176.

69. Hutchison AA: Recovery from hypopnea in preterm lambs: effects of breathing air or oxygen. Pediatr Pulmonol 1987, 3(5):317-323.

70. Saugstad OD, Ramji S, Soll RF, Vento M: Resuscitation of newborn infants with $21 \%$ or $100 \%$ oxygen: an updated systematic review and meta-analysis. Neonatology 2008, 94(3):176-182.

71. Lakshminrusimha S, Russell JA, Steinhorn RH, Swartz DD, Ryan RM, Gugino SF, Wynn KA, Kumar VH, Mathew B, Kirmani K, Morin FC, 3rd: Pulmonary hemodynamics in neonatal lambs resuscitated with $21 \%, 50 \%$, and 100\% oxygen. Pediatr Res 2007, 62(3):313-318

72. Lakshminrusimha S, Steinhorn RH, Wedgwood S, Savorgnan F, Nair J, Mathew B, Gugino SF, Russell JA, Swartz DD: Pulmonary hemodynamics and vascular reactivity in asphyxiated term lambs resuscitated with 21 and 100\% oxygen. J Appl Physiol 2011, 111(5):1441-1447.

73. Lakshminrusimha S, Swartz DD, Gugino SF, Ma CX, Wynn KA, Ryan RM, Russell JA, Steinhorn RH: Oxygen concentration and pulmonary hemodynamics in newborn lambs with pulmonary hypertension. Pediatr Res 2009, 66(5):539-544.

74. Saugstad OD: The oxygen paradox in the newborn: keep oxygen at normal levels. J Pediatr 2013, 163(4):934-935.

75. Klinger G, Beyene J, Shah P, Perlman M: Do hyperoxaemia and hypocapnia add to the risk of brain injury after intrapartum asphyxia? Arch Dis Child Fetal Neonatal Ed 2005, 90(1):F49-F52.

76. Sabir H, Jary S, Tooley J, Liu X, Thoresen M: Increased inspired oxygen in the first hours of life is associated with adverse outcome in newborns treated for perinatal asphyxia with therapeutic hypothermia. J Pediatr 2012, 161(3):409-416.

77. Kapadia VS, Chalak LF, DuPont TL, Rollins NK, Brion LP, Wyckoff MH: Perinatal asphyxia with hyperoxemia within the first hour of life is associated with moderate to severe hypoxic-ischemic encephalopathy. J Pediatr 2013, 163(4):949-954.

78. Barber CA, Wyckoff MH: Use and efficacy of endotracheal versus intravenous epinephrine during neonatal cardiopulmonary resuscitation in the delivery room. Pediatrics 2006, 118(3):1028-1034. 
79. Wyckoff $M H$, Berg RA: Optimizing chest compressions during deliveryroom resuscitation. Semin Fetal Neonatal Med 2008, 13(6):410-415.

80. Harrington DJ, Redman CW, Moulden M, Greenwood CE: The long-term outcome in surviving infants with Apgar zero at 10 minutes: a systematic review of the literature and hospital-based cohort. Am J Obstet Gynecol 2007, 196(5):463. e461-465.

81. Wyckoff MH, Salhab WA, Heyne RJ, Kendrick DE, Stoll BJ, Laptook AR, Network NloCHaHDNR: Outcome of extremely low birth weight infants who received delivery room cardiopulmonary resuscitation. $J$ Pediatr 2012, 160(2):239-244. e232.

82. Redberg RF, Tucker KJ, Cohen TJ, Dutton JP, Callaham ML, Schiller NB: Physiology of blood flow during cardiopulmonary resuscitation. A transesophageal echocardiographic study. Circulation 1993, 88(2):534-542.

83. Schmölzer GM, O'Reilly M, Labossiere J, Lee TF, Cowan S, Nicoll J, Bigam DL, Cheung PY: 3:1 compression to ventilation ratio versus continuous chest compression with asynchronous ventilation in a porcine model of neonatal resuscitation. Resuscitation 2014, 85(2):270-275

84. Schmölzer GM, O'Reilly M, Labossiere J, Lee TF, Cowan S, Qin S, Bigam DL, Cheung PY: Cardiopulmonary resuscitation with chest compressions during sustained inflations: a new technique of neonatal resuscitation that improves recovery and survival in a neonatal porcine model. Circulation 2013, 128(23):2495-2503.

85. Bobrow BJ, Spaite DW, Berg RA, Stolz U, Sanders AB, Kern KB, Vadeboncoeur TF, Clark LL, Gallagher JV, Stapczynski JS, LoVecchio F, Mullins TJ, Humble WO, Ewy GA: Chest compression-only CPR by lay rescuers and survival from outof-hospital cardiac arrest. JAMA 2010, 304(13):1447-1454.

86. Kitamura T, Iwami T, Kawamura T, Nagao K, Tanaka H, Nadkarni VM, Berg RA, Hiraide A, Agency iwgfA-JURotFaDM: Conventional and chest-compressiononly cardiopulmonary resuscitation by bystanders for children who have out-of-hospital cardiac arrests: a prospective, nationwide, population-based cohort study. Lancet 2010, 375(9723):1347-1354.

87. Rea TD, Fahrenbruch C, Culley L, Donohoe RT, Hambly C, Innes J, Bloomingdale M, Subido C, Romines S, Eisenberg MS: CPR with chest compression alone or with rescue breathing. N Engl J Med 2010, 363(5):423-433.

88. Kern KB, Hilwig RW, Berg RA, Sanders AB, Ewy GA: Importance of continuous chest compressions during cardiopulmonary resuscitation: improved outcome during a simulated single lay-rescuer scenario. Circulation 2002, 105(5):645-649.

89. Ewy GA, Zuercher M, Hilwig RW, Sanders AB, Berg RA, Otto CW, Hayes MM, Kern KB: Improved neurological outcome with continuous chest compressions compared with 30:2 compressions-to-ventilations cardiopulmonary resuscitation in a realistic swine model of out-ofhospital cardiac arrest. Circulation 2007, 116(22):2525-2530.

90. Xanthos T, Karatzas T, Stroumpoulis K, Lelovas P, Simitsis P, Vlachos I, Kouraklis G, Kouskouni E, Dontas I: Continuous chest compressions improve survival and neurologic outcome in a swine model of prolonged ventricular fibrillation. Am J Emerg Med 2012, 30(8):1389-1394.

91. Berg RA, Hilwig RW, Kern KB, Babar I, Ewy GA: Simulated mouth-to-mouth ventilation and chest compressions (bystander cardiopulmonary resuscitation) improves outcome in a swine model of prehospital pediatric asphyxial cardiac arrest. Crit Care Med 1999, 27(9):1893-1899.

92. Berg RA, Hilwig RW, Kern KB, Ewy GA: "Bystander" chest compressions and assisted ventilation independently improve outcome from piglet asphyxial pulseless "cardiac arrest". Circulation 2000, 101(14):1743-1748.

93. David R: Closed chest cardiac massage in the newborn infant. Pediatrics 1988, 81(4):552-554.

94. Udassi JP, Udassi S, Theriaque DW, Shuster JJ, Zaritsky AL, Haque IU: Effect of alternative chest compression techniques in infant and child on rescuer performance. Pediatr Crit Care Med 2009, 10(3):328-333.

95. Huynh TK, Hemway RJ, Perlman JM: The two-thumb technique using an elevated surface is preferable for teaching infant cardiopulmonary resuscitation. J Pediatr 2012, 161(4):658-661.

96. Saini SS, Gupta N, Kumar P, Bhalla AK, Kaur H: A comparison of two-fingers technique and two-thumbs encircling hands technique of chest compression in neonates. J Perinatol 2012, 32(9):690-694.

97. Solevåg AL, Dannevig I, Wyckoff M, Saugstad OD, Nakstad B: Extended series of cardiac compressions during CPR in a swine model of perinatal asphyxia. Resuscitation 2010, 81(11):1571-1576.

98. Solevåg AL, Dannevig I, Wyckoff M, Saugstad OD, Nakstad B: Return of spontaneous circulation with a compression:ventilation ratio of 15:2 versus 3:1 in newborn pigs with cardiac arrest due to asphyxia. Arch Dis Child Fetal Neonatal Ed 2011, 96(6):F417-F421.

99. Hemway RJ, Christman C, Perlman J: The 3:1 is superior to a 15:2 ratio in a newborn manikin model in terms of quality of chest compressions and number of ventilations. Arch Dis Child Fetal Neonatal Ed 2013, 98(1):F42-F45

100. Larabee TM, Liu KY, Campbell JA, Little CM: Vasopressors in cardiac arrest: a systematic review. Resuscitation 2012, 83(8):932-939.

101. Nolan JP, Perkins GD: Is there a role for adrenaline during cardiopulmonary resuscitation? Curr Opin Crit Care 2013, 19(3):169-174.

102. Weiner GM, Niermeyer S: Medications in neonatal resuscitation: epinephrine and the search for better alternative strategies. Clin Perinato/ 2012 , 39(4):843-855.

103. Wyckoff MH, Perlman JM: Use of high-dose epinephrine and sodium bicarbonate during neonatal resuscitation: is there proven benefit? Clin Perinatol 2006, 33(1):141-151. viii-ix.

104. Sobotka KS, Polglase GR, Moss TM, Schmolzer GM, Klingenberg C, Davis PG, Hooper SB: Effects of Chest Compressions on Cardiovascular and Cerebral Haemodynamics in Asphyxiated Near-Term Lambs, EPAS2013:4516279; 2007

105. REDDING JS, PEARSON JW: Evaluation of drugs for cardiac resuscitation. Anesthesiology 1963, 24:203-207.

106. Berg RA, Otto CW, Kern KB, Hilwig RW, Sanders AB, Henry CP, Ewy GA: A randomized, blinded trial of high-dose epinephrine versus standarddose epinephrine in a swine model of pediatric asphyxial cardiac arrest. Crit Care Med 1996, 24(10):1695-1700.

107. Burchfield DJ, Preziosi MP, Lucas WW, Fan J: Effects of graded doses of epinephrine during asphxia-induced bradycardia in newborn lambs. Resuscitation 1993, 25(3):235-244.

108. Kleinman ME, Oh W, Stonestreet BS: Comparison of intravenous and endotracheal epinephrine during cardiopulmonary resuscitation in newborn piglets. Crit Care Med 1999, 27(12):2748-2754.

109. Barber CA, Wyckoff MH: Randomized Controlled Trial of Endotracheal Versus Intravenous Administration of Epinephrine During Neonatal Cardiopulmonary Resuscitation in Asphyxiated Piglets, E-PAS2008:63445312. ; 2008.

110. Wyckoff MH, Perlman J, Niermeyer S: Medications during resuscitation what is the evidence? Semin Neonatol 2001, 6(3):251-259.

111. Lucas WW Jr, Preziosi MP, Burchfield DJ: Epinephrine absorption following endotracheal administration: effects of hypoxia-induced low pulmonary blood flow. Resuscitation 1994, 27(1):31-34.

112. McNamara PJ, Engelberts D, Finelli M, Adeli K, Kavanagh BP: Vasopressin improves survival compared with epinephrine in a neonatal piglet model of asphyxial cardiac arrest. Pediatr Res 2014, 75(6):738-748.

113. Morrison LJ, Deakin CD, Morley PT, Callaway CW, Kerber RE, Kronick SL, Lavonas EJ, Link MS, Neumar RW, Otto CW, Parr M, Shuster M, Sunde K, Peberdy MA, Tang W, Hoek TL, Böttiger BW, Drajer S, Lim SH, Nolan JP, Advanced Life Support Chapter Collaborators: Part 8: advanced life support: 2010 international consensus on cardiopulmonary resuscitation and emergency cardiovascular care science with treatment recommendations. Circulation 2010, 122(16 Suppl 2):S345-S421.

114. Lozano R, Wang H, Foreman KJ, Rajaratnam JK, Naghavi M, Marcus JR, Dwyer-Lindgren L, Lofgren KT, Phillips D, Atkinson C, Lopez AD, Murray CJ: Progress towards Millennium Development Goals 4 and 5 on maternal and child mortality: an updated systematic analysis. Lancet 2011, 378(9797):1139-1165.

115. Todres ID, Rogers MC, Shannon DC, Moylan FM, Ryan JF: Percutaneous catheterization of the radial artery in the critically ill neonate. J Pediatr 1975, 87(2):273-275.

116. Msemo G, Massawe A, Mmbando D, Rusibamayila N, Manji K, Kidanto HL, Mwizamuholya D, Ringia P, Ersdal HL, Perlman J: Newborn mortality and fresh stillbirth rates in Tanzania after helping babies breathe training. Pediatrics 2013, 131(2):e353-e360.

117. Ersdal HL, Linde J, Mduma E, Auestad B, Perlman J: Neonatal outcome following cord clamping after onset of spontaneous respiration. Pediatrics 2014, 134(2):265-272. 